\title{
Study of Fundamental Parameter of Soil In Relation To Microwave Remote Sensing
}

\author{
A.C.Paul ${ }^{1}$, A.K.Shrivastava ${ }^{2}$ \\ 1. Research Scholar, Department of Physics, DR.C.V.Raman University Kota, Bilaspur, Chhattisgarh, India. \\ 2. Prof. \& Head, Department of Physics, DR.C.V.Raman University Kota, Bilaspur, Chhattisgarh, India. \\ Email: abhaychandrapaul@gmail.com
}

\begin{abstract}
In this paper an attempt has been made to introduce fundamental parameter of soil in relation to microwave remote sensing. To study soil behviour various parameter that is Physical properties, Chemical properties geographical properties, Physico-chemical properties, has been utilize for calculations of dielectric properties of soil. There are also a lots of models used but empirical model and two point method is highly utilized. The instrument microwave test bench is also used. In research field of soil, characterization of fundamental parameter plays important role. With the help of such parameters following result have been observed in measuring the moisture content. Dielectric constant increases where as electrical conductivity is increases.
\end{abstract}

Keywords: Soil , microwave remote sensing, dielectric properties, model, electrical conductivity.

\section{INTRODUCTION-}

The role of soil is very important in the development of human being. The soil is simply the upper layer of ground which is useful supporting life. A lot of scientists, agriculturists defined soil. Soil is the upper part of earth crust in which plants are anchored. soil is the upper weathering layer. Soil is a natural body developed by natural forces acting an natural materials. It is usually differentiated into horizons of materials and organic constituent of variable depths which differ from the parent materials in morphology, physical constituents, chemical, properties, composition and biological characteristics. Soil is the topmost layer of earth crust capping the rock. Soil is made up different components as mineral particles, dead organic matter or humus, soil atmosphere, soil water and biological system or soil microorganisms. The minerals represent about $90 \%$ of the total weight of the soil. Imports elements which are found in compound state are oxygen, $\mathrm{Si}, \mathrm{Fe}, \mathrm{Al}$, N.P. K, Ca, Mg, C, H, etc [1] . Although there are eighteen main nutrients in the soil. Nitrogen in the form of nitrogen salt occurs from atmosphere organic matter is also called humus. The role of humus is also important. The main elements found in humus are carbon, hydrogen, oxygen, sulpher and nitrogen. The main compound found in humus are carbohydrates, phosphoric acid, some organic acids, fats, resins, area etc. Humus is a dynamic product and is constantly varying became of its oxidation, reduction and hydrolysis. Thus it can be said that humus has no definite chemical composition, it has much carbon content and less nitrogen humus is not soluble in water and less nitrogen humus is not soluble in water. It is present in the soil in the form of organic colloids. The amount of human is different soils vary greatly humus percentage in the soil is affected by climatic and biological factors. It is less in arid soils and very high in humid soils. In the top layer of the soils humus quantity is greater than in the deep layers In dark humid areas which are thickly covered with vegetation.

\section{THEORETICAL CONSIDERATION-}

The soil has physical chemical as were as well as electrical properties. Besides these soil has different proportions as soil mineralogy, soil biology, soil chemistry, soil physical etc. There are above fifty model to evaluate dielectric behviour of the soil, But Wang and Schmugge model is very relevant and practical method. Wang and Schemugge proposed an empirical model to describe the dielectric behaviour of soil water mixture using the transition moisture as an adjustable parameter, The model is based mainly an two observations: (i) for all soil samples the dielectric constant increases slowly initially with moisture content upto transition moisture after which it increases steeply with moisture content , (ii) The transition moisture is found to vary with texture of the soil, being smaller for sandy soils than that for high clay content soils. The wilting point $(\mathrm{Wp})$ of a soil is percent of dry weight of the soil represented as [2],

$$
\mathrm{Wp}=0.06774-0.00064 \mathrm{X} \text { sand }+0.00478 \mathrm{X} \text { clay }
$$

Where sand and clay are the sand and clay contents in percent of dry weight of a soil. The Wp characterizes a stage of $\mathrm{Wc}$ in the soil water system 


\section{Available online at www.ijrat.org}

. Between $\mathrm{Wp}$ and field capacity attraction, At Wc $\geq \mathrm{Fc}$, water flows with gravity, further at $\mathrm{Wc} \leq \mathrm{Wc}$, it is difficult for crops to extract water from soil, water help in soils at temperature up to $105^{\circ} \mathrm{c}$ is called hygroscopic water (at soil tension of 3 , bar) and is virtually a part of the mineral structure of the soil.

The transition moisture of the soil is calculated as.

$\mathrm{Wt}=0.49 \mathrm{Wp}+0.165$

For the moisture contents less than transition moisture $\mathrm{Wt}$, most of the water molecules are tightly bound to the soil particles called bound water, There are a lot of parameter regarding dielectric behaviour of soil as $[3],[4]$,

- $\quad$ texture (Sand, silt, clay)

- Bulk density

- Particle holding capacity

- Wilting point

- Field capacity

- Transition moisture

- Hydraulic conductivity

- Colour

- $\mathrm{pH}$

- Electrical Conductivity

- Organic carbon

- Calcium Carbonate

- Available Nitrogen

- Phosphorus

- Available - Potassium

- Available- Iron

- Available-Mn

- Available-Zn

- NPK-Fertilizer

- Dielectric-Constant

- Dielectric-loss

- Tangent-loss

- Microwave-Conductivity

- Relaxation-Time

- Emissivity-

- LALA

- Complex dielectric constant

There are several models as well as technique to calculate electrical properties of soil following no are the Models [3] :

There are no. of methods and models which is as follows,

- A sensing technique

- Approximation model

- Automatic measurement system
- Cavity Method

- Coaxial Perturbation technique

- Coaxial Probe method

- Colloid dielectric Probe

- Data processing technique

- Dielectric spectroscopy technique

- Digital elevation model approach

- Dobson model

- Elmake model 7200

- Empirical Model

- Four Component -dielectric mixing model

- Four Component-Theoretical model

- Free space method

- Geo metric options model

- Gravimetric method for water content measurement using soil science.

- Hewielt Packearel Model 8540

- HP Network analyzer (HP8510-C) \& HP dielectric Probe $(85070 \mathrm{~m})$ employing coaxial probe method.

- Infinite sample method

- Key sight 85070 E dielectric probe

- Micro Strip transmission live

- Model generation

- MVA (Multiple view angle ) approach

- Open-structure technique

- Perturbation model

- Physical optic model

- RADAR approach

- Resonator model

- Roberts \& van Hipple experimental technique.

- Semi empirical model

- Six-port-reflectometry

- Soil testing kit(Model-161)

- SSM inversion method

- Stern - Gowy double layer

- TDR-(Time Domain Reflectometry) for measuring soil water content.

- Theoretical model/Technique/ICTP

- Transmission Method

- Two Point method

- Vector Network Analyzer

- Wang and Schmugge model

- Waveguide Cell method.

\section{RESULTS \& DISCUSSION}

Dielectric Properties of the soil depends on the activity of permanent, electrical dipoles, ionic conduction, and degree of dipole alignment [5] . It has been found that dielectric constant of soil depends an moisture contents and frequencies.

Dielectric and emissivity perhaps play very important role in the 


\section{Available online at www.ijrat.org}

hydrological research [6]. It has been seen that dielectric constant of soil Increases with increasing percentage of water constant.

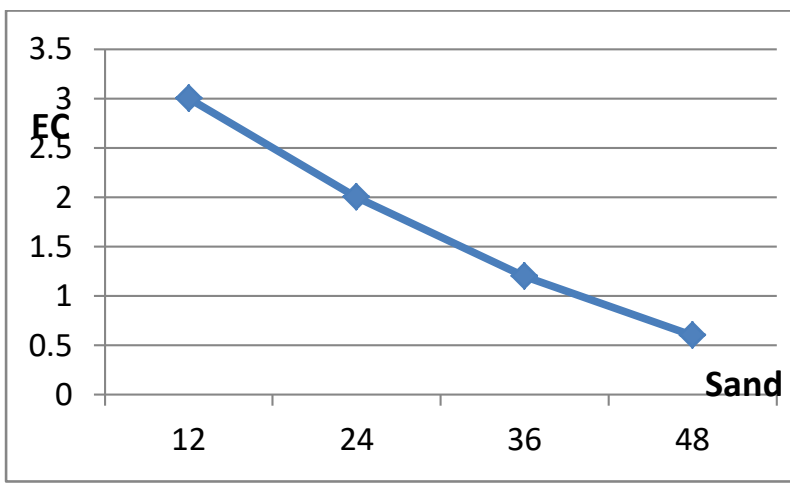

Fig. Variation of Electrical Conductivity with texture of black Soil.

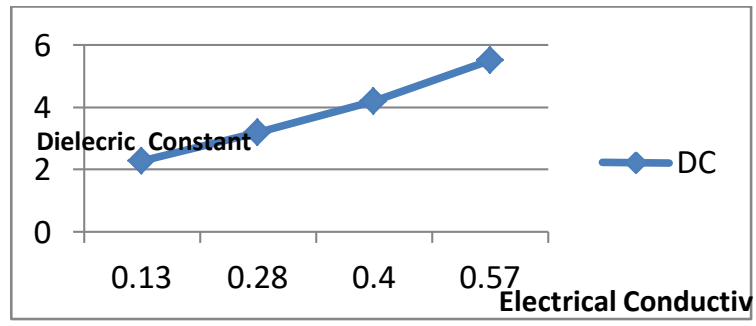

Fig. Variation of Electrical Conductivity with DC of Black Soil

\section{CONCLUSIONS-}

Following points are the conclusions which are given below,

- Dielectric Constant of dry soil is nearly 3.0.

- Increasing the moisture constant dielectric constant is increases

- Increasing the percentage the clay the dielectric constant decreases.

- Dielectric constant decreases where as porosity in soil increases.

- Dielectric constant decreases where as in bulk density increases

- Dielectric constant Increases where as $\mathrm{pH}$ increases.

- Dielectric constant increases were as EC is increases.

- Dielectric constant increases were as OC increases.

- Dielectric cont Increase where as Nitrogen. Increase.
- Dielectric constant increase were as Phosphor is increases.

- D.C. increases were as $\mathrm{K}$ increases.

- D.C. increase were as Fe increases.

- D.C. increase were as $\mathrm{Zn}$ increases.

- D.C. increase were as $\mathrm{Cu}$ increases.

- D.C. increase slowly at constant Mn.

\section{ACKNOWLEDGEMENT-}

The authors are highly thankful to Dr. S.K.Shrivastava, Prof. \& Head, Department of Physics, R.G. Govt. P.G. College Ambikapur(C.G.) and Prof. Ashutosh Pandey, Department of Physics, DR.C.V.Raman University Kota, Bilaspur, (C.G.).

\section{REFERENCES-}

[1] P.R. Chaudhari D.V. Ahire, V.D. Ahire, "Variations of Dielectric Constant of Dry Soil With Their Physical Constituents and Available Nutrients at C-Band Microwave Frequency", Journal of Chemical, Biological and Physical Sciences, 2(2), PP1001-1009, 2012.

[2] S.K.Srivastava and G.P.Mishra " Study of the Characteristics of the Chhattisgarh at X-Band frequency" Sadhana,Vol. 29, part 4,pp 343-347 august 2004 .

[2] Patel Lakhapati et al.," Role of Moisture Content and Dielectric Constant In soil, International Journal of Research in Advent Technology, Vol, 6,No. 11, PP-3288-3293, 2018.

[3] Patel Lakhapati et al , "Significance of Dielectric Behaviour of Flood Affected Soil in Agriculture, With Special Reference to Bihar and Chhattisgarh, International Disciplinary Research Journal, Vol-09, issue 01 PP 67-72, 2019.

[4] .Biswas T.D. and Mukherjee S.K. , 'Textbook of Soil Science", TMH Publishing Company Limited New Delhi, ISBN- 13:978-0-07462043-4, ISBN; 10:0-07-462043-6, 2008.

[5] Patel Virendra Kumar N. , "Variation of Electrical Parameters of Soil With Moisture And Salinity Over Frequency Range From 20 $\mathrm{Hz}$ to $2 \mathrm{MHz}$, International Journal of Scientific Research And Reviews, 7(1), 457471, 2018.

[6] Patel Uma, et al, "Study about Remote Sensing, Its Process, Types, Applications and Advantages", International Journal of Engineering Science \& Research, ISSN: 22779655, Scientific Journal Impact Factor: 3.449, 2014. 